\title{
Representações identitárias no processo de seleção de talentos
}

\author{
Prospero Brum Paoli* \\ Felipe Rodrigues da Costa** \\ Amarilio Ferreira Neto*** \\ Antonio Jorge Gonçalves Soares****
}

\begin{abstract}
Resumo: O objetivo do estudo é descrever e analisar o processo de detecção e seleção de talentos considerando as representações identitárias e práticas no cotidiano do futebol. Utiliza como instrumento entrevistas semiestruturadas, aplicadas aos treinadores e coordenadores das categorias Sub 15, Sub 17 e Sub 20, e observadores técnicos em sete clubes da primeira divisão do futebol brasileiro. Conclui que o discurso identitário sobre o ideal proclamado do futebol brasileiro, o futebol-arte, não orienta as ações dos profissionais envolvidos no processo de seleção e treinamento de talentos. Todavia, esse discurso pode apresentar eficácia simbólica no processo de comercialização de jogadores.
\end{abstract}

Palavras-chave: Futebol. Brasil. Identidade. Talento.

\section{INTRODUÇÃO}

Giulianotti (2002) afirma que o futebol é uma das grandes instituições culturais que, em conjunto com a educação e os meios de comunicação de massa, formam e consolidam identidades nacionais. Esse esporte e seus processos de difusão e informação instituições esportivas, mídias, literatura, cinema, lazer e análises acadêmicas - produzem e disseminam valores, gostos e sentimentos que contribuem para que o indivíduo e as coletividades se localizem

\footnotetext{
*Doutor em Educação Física. Professor do Colégio Universitário da UFV. E-mail: prosperopaoli@bol.com.br.

**Doutorando em Educação Física (UGF). Email: fcostavix@gmail.com.

***Doutor em Educação. Professor do Centro de Educação Física, UFES. amariliovix@gmail.com.

****Doutor em Educação Física. Professor da Faculdade de Educação, UFRJ. ajsoares@globo.com.
} 
e se identifiquem num dado sistema social e cultural. A partir desse pressuposto, vários estudos no campo das ciências sociais foram realizados no Brasil e na América Latina nas últimas três décadas, discutindo os processos de construção de identidades a partir do futebol e de outros esportes (DAMATTA, 1982; ROSENFELD, 1993; LEITE LOPES, 1994; ARCHETTI, 1994, 1999; MURAD, 1996; GUEDES, 1998; TOLEDO, 2001; HELAL et al., 2001; FIENGO, 2000, 2003; GASTALDO, 2000; SANTOS NETO, 2002; AGOSTINO, 2002; ALABARCES, 2002; DAMO, 2002; SOARES, 2003).

Como os processos de construção de identidades são sempre relacionais, tais estudos caminharam em dois níveis: um mais próximo das narrativas dos Estados-nações e outro que se aproxima das tensões vividas diante dos processos de globalização e do crescente movimento reivindicatório das minorias no interior desses estados. É possível, então, conceituar esses níveis como: a) afirmação de diferenciações e de identificações a partir da comparação entre as grandes unidades (estados nacionais); e b) afirmação das diferenças, semelhanças e hibridização a partir do tenso e complexo processo relacional de identificações e pluri-identificações presentes na pósmodernidade ou na modernidade tardia.

Esse processo de afirmação de identidades é atravessado pelas diferentes formas de identificação no mundo contemporâneo (etnia, gênero, classe etc.) e ocorre por meio de negociações, resistências, apropriações, confrontações e diálogos a partir dos diferentes olhares e lugares. Mesmo no espaço do futebol, existe hoje uma espécie de pluri-identificação, pois os agentes (torcedores, dirigentes, jogadores) identificam-se com seleções, clubes locais e internacionais, jogadores de diferentes nacionalidades e etnias e, ainda, com empresas vinculadas, direta ou indiretamente, ao esporte.

Apesar dessas possibilidades de estudos sobre a relação futebolidentidade, pode-se afirmar que boa parte da produção brasileira sobre o assunto se concentrou no primeiro nível, isto é, em analisar os processos de construção identitária do estilo brasileiro de jogar

Movimento, Porto Alegre, v. 16, n. 04, p. 135-150, outubro/dezembro de 2010. 
futebol sob a perspectiva do país como uma comunidade imaginada, nos termos de Anderson (1983).

Para Soares e Lovisolo (2003), na década de 1920 os bons resultados do futebol brasileiro e o processo de massificação dessa prática foram sendo englobados nas narrativas de construção nacional. A partir de 1930, o futebol legitima-se como pura expressão da nacionalidade nas narrativas de Mário Filho, José Lins do Rego, Gilberto Freyre e de outros jornalistas, intelectuais e literatos (SOARES, 2003). O estilo marcado pela virtuose individual começou a ser exaltado como marca de singularidade que o Brasil teria imprimido com relação ao modelo anglo-saxão de futebol.

Dessa forma, como afirma Rodrigues (2004), muitos estudos referentes ao futebol brasileiro preconizam que o sucesso do Brasil se legitimou via atributos da raça negra e da miscigenação. Entretanto, deve-se considerar que algumas narrativas acerca da forma brasileira de jogar futebol são marcadas por visões românticas sobre esse esporte e sobre a identidade nacional. Tais narrativas, construídas a partir da trajetória vitoriosa do futebol brasileiro, acabaram por construir uma marca valorizada no mercado desse esporte. No mercado internacional, o futebol brasileiro é classificado como o beautiful game. Assim, a identidade do jogador brasileiro está associada à ideia do jogo bonito ou do futebol alegre e vitorioso.

Nesse sentido, podemos pensar que os atores sociais e as instituições do futebol no Brasil, no que se refere à detecção e seleção de jogadores, teriam uma tendência a orientar suas ações pedagógicas ou criar critérios de escolha tendo como referência a cultura futebolística local, regional ou nacional, em interação com as imagens do "bom" futebol partilhadas pelo grupo ou comunidade. A questão que se coloca é a seguinte: as representações identitárias sobre o futebol brasileiro, marcadas pelo beautiful game, praticado pelos magic players (ou fantasistas, como preferem os italianos), orientam as práticas de seleção e detecção de talentos?

Os objetivos do artigo são: analisar o grau de proximidade e interação entre representações identitárias e práticas no cotidiano desse esporte; descrever e analisar o processo de detecção e seleção de

Movimento, Porto Alegre, v. 16, n. 04, p. 135-150, outubro/dezembro de 2010. 
talentos, identificando em que medida o estilo de jogo brasileiro (futebolarte ou beautiful game) produz critérios ou indicadores partilhados por profissionais responsáveis pela detecção e seleção de talentos.

\section{Metodologia}

O plano teórico-metodológico foi construído a partir do debate suscitado pelas Ciências Sociais e pela Educação Física, para trabalhar, conceitual e operacionalmente, as noções de cultura e os processos de construção de identidade. Nesse sentido, tomamos inicialmente a distinção indicada por Cuche (1999, p. 176) como um pressuposto de análise:

A cultura pode existir sem consciência de identidade, ao passo que as estratégias de identidade podem manipular e até modificar uma cultura que não terá então quase nada em comum com o que ela era anteriormente. A cultura depende em grande parte de processos inconscientes. A identidade remete a uma norma de vinculação, necessariamente consciente, baseada em oposições simbólicas.

Para a pesquisa foram selecionados sete clubes, pertencentes à primeira divisão do futebol brasileiro, que possuem instituídos os processos de formação, detecção e seleção de talentos para o futebol profissional. Da Região Sul foram selecionados os clubes Grêmio Football Porto Alegrense, Sport Club Internacional (RS) e o Paraná Clube (PR); da Região Centro-Oeste foi selecionado o Goiás Esporte Clube (GO); e da Região Sudeste, o Cruzeiro Esporte Clube (MG), o Fluminense Football Club (RJ) e o São Paulo Futebol Clube (SP).

A escolha dessas regiões se deu em função do discurso nativo, por vezes confundido com o dos analistas sociais do esporte ${ }^{1}$, que aponta a existência de diferentes "escolas, estilos de jogo e culturas"

${ }^{1}$ Ao abordar o tema do estilo de jogo, Giulianotti (2002) afirma que os times do Rio de Janeiro são os verdadeiros pioneiros da estética sul-americana, com um estilo exibicionista e rítmico, fluindo entre a construção cuidadosa da condução da bola e o ataque repentino. Já as equipes do Rio Grande do Sul empregariam uma abordagem mais à "uruguaia", jogando frequentemente com uma forte determinação de vencer, não importando os meios, e até utilizando a força física como elemento principal.

Movimento, Porto Alegre, v. 16, n. 04, p. 135-150, outubro/dezembro de 2010. 
no Brasil. Além disso, essas regiões concentram boa parte do mercado de formação nas categorias de base.

Com o objetivo de reunir explicações e interpretações sobre o processo de formação, detecção e seleção de jogadores de futebol no Brasil, realizamos entrevistas semiestruturadas com 38 profissionais envolvidos diretamente no processo de formação de jogadores, a saber: coordenadores técnicos, profissionais que supervisionam o trabalho realizado nas categorias de base dos clubes, treinadores das categorias Sub-15, Sub-17 e Sub-20 e observadores técnicos ${ }^{2}$ das categorias de base dos sete clubes pertencentes ao corpus da pesquisa. As entrevistas foram realizadas nos centros de treinamento. Os atores envolvidos foram informados sobre os aspectos éticos da pesquisa e assinaram o Termo de Conhecimento Livre e Esclarecido. As entrevistas foram transcritas na íntegra e depois analisadas em triangulação com as observações do trabalho de campo e com a literatura técnica e socioantropológica do futebol.

\section{A seleÇão de TALENTOS NO FUTEBOL BRASILEIRO}

A questão relacionada com a detecção, seleção e promoção de talentos no esporte, com foco na teoria e metodologia, tem gerado diversas discussões tanto no âmbito acadêmico quanto na prática cotidiana dos clubes.

Em décadas passadas, não havia muita necessidade de se buscar precocemente jogadores para serem promovidos à categoria profissional, embora os jogadores de alta competência fossem alçados para a equipe principal quando eram considerados virtuosos no esporte. O jogador Pelé é um exemplo disso ${ }^{3}$. Não existia a necessidade de profissionalizar rapidamente o jogador porque a estrutura do mercado era diferente. A existência do passe ${ }^{4}$ permitia ao clube aguardar o momento exato de

${ }^{2}$ Profissionais contratados pelos clubes, em regime de exclusividade, observando, detectando e selecionando jogadores nas diversas competições que são organizadas no País.

${ }^{3}$ Pelé inicia sua carreira na Seleção Brasileira aos 17 anos, disputando a Copa do Mundo de 1958 na Suécia, marcando gol na partida final contra a seleção anfitriã. Foi campeão do mundo em outras duas oportunidades (1962 e 1970).

${ }^{4}$ No futebol, "passe" é o valor indenizatório que o clube recebe pela transferência do atleta.

Movimento, Porto Alegre, v. 16, n. 04, p. 135-150, outubro/dezembro de 2010. 
negociar o jogador ou utilizá-lo em sua equipe principal. O mercado do futebol e sua legislação se transformaram a partir de três eventos: o caso Bosman ${ }^{5}$, a estratégia geopolítica de difusão do futebol pela Fédération Internationale de Football Association (FIFA) e, consequentemente, a globalização e a consolidação do mercado consumidor desse esporte no planeta.

Atualmente, os clubes e empresários investem para revelar precocemente seus potenciais talentos esportivos, pois o risco de perder o capital investido na formação é alto, em virtude da ampliação dos direitos legais do jogador e da legislação que favorece as transferências em nível nacional e internacional. Assim, a precocidade deixou de ser exceção para constituir-se em regra. Por exemplo, um jogador da categoria Sub-17 que não tenha sido convocado para participar, mesmo como reserva, da equipe profissional de seu clube provavelmente terá menos chances de entrar para o mercado profissional desse esporte, segundo revelaram nossos entrevistados.

Antes se hesitava em lançar jovens com potencial entre os profissionais para não pular etapas do seu processo de formação. Atualmente, a necessidade de identificar o "talento" da forma mais precoce possível está diretamente articulada aos processos de globalização do mercado, transformando o futebol brasileiro em um dos principais centros formadores de "pés de obra"6 (DAMO, 2005; SOARES; BARTHOLO, 2009). Além disso, a crise financeira em que estão mergulhados os clubes de futebol no Brasil os leva a investir mais rapidamente na formação e na negociação do atleta. Isso também coincide com os projetos familiares dos jovens jogadores (RIAL, 2006; SOUZA et al., 2008).

\footnotetext{
${ }^{5}$ Em 1995, a "Lei Bosman" muda o cenário do futebol europeu, quando Jean Marc Bosman recorre à corte europeia reivindicando liberdade para transferir-se para outro clube ao final de seu contrato de trabalho (COELHO, 2009).

${ }^{6}$ Neologismo utilizado para se referir aos jogadores de futebol, em substituição à expressão "mão de obra", pois as "ferramentas" de trabalho dos jogadores de futebol são os pés.

Movimento, Porto Alegre, v. 16, n. 04, p. 135-150, outubro/dezembro de 2010.
} 


\title{
4 Aescola de Apolos com pequenos traços de Dionísio: CRTTÉRIOS DE SELEÇÃO DE TALENTOS E A IDENTIDADE DO BRASILEIRO
}

Um novo paradigma surgiu no contexto cultural emergente do futebol e requer novos parâmetros, fornecidos pelos diversos atores sociais envolvidos no processo de formação de jogadores e que acabam por orientar o processo de descoberta de novos talentos.

\begin{abstract}
Há no Brasil atualmente um consenso em torno da imagem do jogador de futebol "moderno": disciplinado, forte, combativo, boa estatura, bem preparado fisicamente e taticamente consciente, com um eficiente sentido de formação tática, brasileiramente convivendo com o jogador criativo e talentoso que desequilibra o jogo tático com sua habilidade técnica (TÉCNICO DA CATEGORIA SUB-15) ${ }^{7}$.
\end{abstract}

Nessa perspectiva, começa a sofrer alterações o entendimento "clássico" sobre o que era um profissional de "talento": o jogador virtuoso era aquele que, além de eficiência, apresentava arte e beleza na execução dos fundamentos do futebol. Dominar a técnica do drible era indicador fundamental para definir o jogador talentoso no Brasil. O talento no futebol se associava diretamente ao domínio de técnicas corporais que permitissem o controle da bola com os pés e demais partes do corpo. Portanto, um jogador que fosse hábil apenas em retomar a posse de bola, desarmar o ataque ou realizar uma marcação eficiente não era visto como um virtuoso em nossa cultura. Para os atuais especialistas, o jogador talentoso é aquele que possui um conjunto maior de qualidades: técnicas (habilidades corporais de variadas naturezas e funções), táticas, físicas, psicológicas, emocionais, culturais e sociais ${ }^{8}$.

Hoje manda muito a qualidade técnica e o biotipo. O futebol é muita força. O jogador não pode ter

${ }^{7}$ Para mais informações sobre as entrevistas utilizadas neste artigo, ver Paoli (2007). ${ }^{8}$ Podemos citar o jogador brasileiro Kaká. Um jornal eletrônico destaca, em matéria especial sobre o jogador, intitulada "La radiografía de Kaká": "[...] su velocidad, visión de juego, habilidad para combinar y capacidad para definir le permiten finalizar muchas jugadas a la contra en gol". Ou seja: força, habilidade, técnica, controle, características que o fazem "[...] uno de los futbolistas con mayor calidad del mundo" (MARCA.COM., 2009).

Movimento, Porto Alegre, v. 16, n. 04, p. 135-150, outubro/dezembro de 2010. 
problema nas divididas, nas bolas aéreas. Por isso deve-se aliar a habilidade técnica com a velocidade. Mas acontece de você ver um zagueiro bom tecnicamente, mas a estatura é baixa, então não adianta, a altura não o deixa jogar de zagueiro. Mas, dependendo de sua habilidade técnica, pode ser adaptado de lateral, volante. Por outro lado, você observa um jogador de meio-campo que é muito franzino e aí tem que avaliar se ele vai conseguir evoluir até chegar no profissional. Porque, neste caso, temos à disposição alguns exames que determinam se o garoto vai crescer (OBSERVADOR TÉCNICO).

Ao nos remetermos ao pensamento de Soares e Lovisolo (2003a, 2003b) de que a "arte" e a "força" no futebol passaram a representar duas correntes que se opõem no modo de pensar sobre o estilo de jogar, uma terceira corrente é favorável a uma posição conciliatória entre a "força" e a "arte".

Durante uma partida de futebol, as equipes tendem a alternar ou combinar esses dois estilos de jogo. As próprias circunstâncias do jogo, como a necessidade de vitória, o fato de jogar fora de casa, a perda de um jogador por expulsão e as qualidades do adversário acabam por influenciar na adoção ou não de um estilo mais racional, metódico, pragmático, com ênfase no aspecto defensivo.

Parreira ${ }^{9}$, por exemplo, destaca que atualmente, para uma equipe obter sucesso no futebol, é necessário contar com todos os recursos possíveis: os talentos individuais, a garra, a vontade, o poder de marcação e a racionalidade. Para treinadores e jogadores, o que importa é a vitória, e não o "jogo bonito"10.

As entrevistas confirmaram essa realidade, revelando uma ênfase dos treinamentos para atender a critérios físicos, táticos e

${ }^{9}$ Entrevista ao Programa Arena Sportv, do Canal 39, Sportv, em 28-03-05.

${ }^{10}$ Entrevista de Robinho, jogador da Seleção Brasileira, ao Programa Globo Esporte da TV Globo, em 28-03-05: "O importante em uma partida de futebol, ainda mais se tratando de Eliminatória de Copa do Mundo, são os três pontos. Não importa se venceu de um ou de quatro. No futebol, onde existe a obrigatoriedade de vencer e em competições equilibradas, não adianta jogar bonito e empatar ou perder, ou seja, tem que se satisfazer com a vitória, mesmo com um placar apertado, e abrindo mão do futebol técnico".

Movimento, Porto Alegre, v. 16, n. 04, p. 135-150, outubro/dezembro de 2010. 
técnicos. Essa necessidade orienta a forma como os jogadores são observados pelos atores envolvidos em sua formação. Com base na literatura específica do futebol e nas entrevistas da pesquisa de campo, vários são os requisitos que o jogador de futebol necessita para o desempenho de suas funções:

\begin{abstract}
A vitrine hoje é a Europa. O garoto tem que ter um prognóstico de altura. A preferência é contar com garotos altos. Nós temos um protocolo, que chamamos de modelo matemático de seleção de talentos. Neste protocolo procuramos observar a forma de indicação do garoto, ou seja, como ele chegou ao Clube. Tem um peso. Observamos as manifestações de ansiedade, de mobilização para jogar bola. Depois, como ele se encontra na parte física: força, velocidade, agilidade, aspectos antropométricos. Depois observamos a habilidade motora, que chamamos de técnica. Observamos a parte motora para o drible, o passe, a condução de bola. E o último, é o que chamamos de inteligência de jogo, a parte tática. Como ele se porta em campo, como ele aparece para receber a bola, como joga sem a bola. São cinco indicadores (COORDENADOR TÉCNICO).
\end{abstract}

O protocolo citado consegue fazer um levantamento das características físicas do atleta, porém, no que diz respeito à virtuose do atleta, a forma de analisá-la ainda seria o "olho clínico" (ou feeling), ou seja, a experiência do observador técnico que, ao ver o jogador atuando, é capaz de dizer se ele tem ou não potencial para fazer parte do quadro profissional do clube. A capacidade do observador em perceber o valor dos talentos é fundamental dentro do mercado do futebol, evitando perda do investimento (CHRISTENSEN, 2009).

Diversos fatores estão envolvidos na avaliação do jogador e, segundo os especialistas do futebol, a disciplina do atleta é fundamental. Essa é uma característica que se refere à dedicação aos treinamentos, à obediência, às determinações táticas e ao comportamento "extracampo". Isso quer dizer que o atleta é observado também na sua vida privada. Durante sua formação, ser 
jogador de futebol significa representar um papel social de "bom moço"11 para treinadores, empresários, torcedores e imprensa.

Nos clubes pertencentes à amostra deste estudo, foi possível perceber que existem normas estritas a serem seguidas pelos jogadores. As regras de conduta são ditadas por um regulamento que normatiza as atitudes dos jogadores em todos os setores do Centro de Treinamento (CT). Em todos os clubes pesquisados, o controle é rígido, sendo adotada uma cartilha disciplinar que controla o comportamento dos atletas nos alojamentos, nos campos, na sala de musculação, departamento médico e no refeitório. Além disso, veta a prática de atividades esportivas fora do clube, frequência a bares e boates nas horas de folga, bem como a ingestão de bebidas alcoólicas, e, aos atletas que vivem no CT, a entrada fica impedida após as 23 horas $^{12}$.

Os especialistas entendem que a formação do atleta requer ascetismo, ou seja, o futebol, para além do talento, só se desenvolve com disciplina, empenho e dedicação, como quase tudo na vida. Poder-se-ia dizer, segundo acreditam os especialistas, que no momento em que o atleta se conscientiza da importância da disciplina, ele melhora suas condições para o desempenho em campo. A disciplina ascética no esporte é fundamental na formação desse produto chamado "atleta" (VAZ, 1999).

O mercado do futebol exige do atleta das categorias de base um ethos típico do futebol profissional, empresarial e espetacular. A busca pela disciplina vai ao encontro do profissionalismo, que é cada vez mais reivindicado em todos os setores, fazendo com que o clube gerencie não só o trabalho, mas também a vida social do jogador, que é controlada em todos os aspectos. A imagem do jogador brasileiro como oriundo das camadas desprivilegiadas economicamente e

\footnotetext{
${ }^{11} \mathrm{O}$ conceito de bom mocismo perpassa por uma moralidade marcada no corpo. Fraga (2000, p. 105) conceitua bom mocismo dentro de uma lógica cristã, em que a "[...] gestualidade passa a ser mediadora dos processos de incorporação da boa moral, tornando-se o lugar de verificação do domínio do espírito sobre o corpo nos mínimos detalhes". Pode-se trazer para o futebol a compreensão de que o bom moço é aquele que consegue dominar seus instintos (suas vontades carnais), comportar-se em favor da razão (tornar-se jogador).

${ }^{12}$ Normas que constam no Manual de Conduta da equipe paranaense.
}

Movimento, Porto Alegre, v. 16, n. 04, p. 135-150, outubro/dezembro de 2010. 
despossuídas de capital cultural potencializa a imagem do futebol como civilizador e redentor dessa população juvenil. O argumento redentor que aparece na representação nativa dos especialistas é o de que o esporte reduz as estatísticas de criminalidade da juventude. Aqui o mercado de formação de atletas aparece amalgamado com os ideais educativos e civilizadores das classes "perigosas".

Nos clubes estudados, é exigida dos jogadores uma disciplina rígida, levando-se em consideração a lógica empresarial, pois, segundo a maioria dos entrevistados, o futebol demanda competitividade, disciplina e atitude profissional. Cabe lembrar que a boemia, presente no futebol em boa parte do século XX, e por vezes relevada ou até romantizada, tornou-se um mal a ser combatido nesse campo profissional. Isso é o que se espera de um jogador moderno. Nesse contexto, espera-se também que o jogador tenha uma visão de futuro, sem esquecer que a profissão dura no máximo 20 anos.

Nas entrevistas e nos contatos com os especialistas, foi possível perceber a convicção de que o jogador que não tiver essa disciplina dificilmente alcançará seu objetivo de tornar-se profissional. $\mathrm{Na}$ opinião deles, o futebol exige renúncia das atividades comuns à faixa etária dos jovens atletas. Além disso, dizem os especialistas, no futebol moderno o jogador deve desempenhar funções tanto ofensivas quanto defensivas, além de ter um bom controle da bola quando está em sua posse. A nova configuração do futebol moderno demanda um perfil mais generalista, sem que o jogador renuncie à sua especialidade em campo.

A modernização do futebol no Brasil exige uma formação voltada para as demandas do mercado. Poder-se-ia pensar que esse modelo de atleta, idealizado pelos clubes estudados em suas categorias de base, se aproxima das representações do futebol-força, que retrata o bom jogador como disciplinado, racional e metódico. No entanto, no campo profissional do futebol, os especialistas conciliam em seus discursos essas qualidades da "força" associadas à criatividade, pois seria a imagem da ruptura, do fantástico, que tornaria belo e imprevisível o espetáculo do futebol.

Movimento, Porto Alegre, v. 16, n. 04, p. 135-150, outubro/dezembro de 2010. 
A cultura nacional opõe estruturalmente o futebol-força ao futebol-arte ou, nos termos de Gilberto Freyre (1947), o futebol apolíneo ao futebol dionisíaco (tipicamente brasileiro para esse intelectual). Assim, os especialistas do futebol acabam por indicar que jogador excepcional é aquele que, sendo Apolo, apresenta traços de Dionísio. Entretanto, o dia a dia do futebol é uma escola de Apolos.

\section{CONCLUSÕES}

O discurso identitário sobre o proclamado futebol brasileiro, o futebol-arte, não é o marco orientador das ações dos atores sociais que estão envolvidos no processo de seleção de talentos. Esse processo está estruturado a partir de um "projeto pedagógico" calculado, controlado e administrado em função dos objetivos mercadológicos que envolvem a formação de jogadores de futebol como um produto para ser absorvido pelo mercado. Todavia, o discurso do futebol-arte pode apresentar eficácia simbólica no processo de comercialização de jogadores ou nos jogos de identidade.

A formação dos jovens futebolistas brasileiros não está pautada pelo beautiful game. Essa formação é orientada por um mercado que valoriza jogadores com características mais aproximadas do conhecido futebol-força, atletas de características físicas privilegiadas, que conseguem submeter-se ao sistema de disciplina.

Contrapondo-se ao mito do jogador brasileiro dotado de um "dom" natural, "pronto desde que nasce", o processo de avaliação e formação, como foi observado, é contínuo, trabalhoso e de longo prazo, mesmo quando baseado nos resultados ou na intuição dos especialistas. O talento não pode ser detectado com base na aptidão demonstrada em uma única avaliação e/ou mensuração, mas essa identificação é parte de um processo que se torna eficaz durante as etapas dos treinamentos, das avaliações e mensurações sistemáticas, concomitantemente com a participação em competições esportivas. Esse seria o ideal revelado pelos atores sociais dos clubes pesquisados por este estudo. Na pesquisa de campo, foram entrevistados os observadores, os coordenadores e os técnicos das categorias de

Movimento, Porto Alegre, v. 16, n. 04, p. 135-150, outubro/dezembro de 2010. 
base, ou seja, a representação dos discursos oficiais dos clubes, daqueles que estão no poder. Acreditamos que outros estudos poderiam dar voz aos demais atores sociais, entre eles os atletas e empresários.

\begin{tabular}{l}
\hline Identitary Representations in the Talent \\
Selection Process \\
Abstract: The study's aim is to describe and analyze \\
the talent selection and detection process considering \\
the identitary representations and daily practices of \\
soccer. It uses as instrument half structured \\
interviews, applied to coaches and coordinators of U- \\
$15, U-17$ and U-20 categories, and technical observers \\
in seven clubs of Brazilian soccer First Division. It \\
concludes that the identitary discourse on the \\
proclaimed ideal of Brazilian soccer, the art soccer, \\
does not guide the actions of the involved \\
professionals in the talent selection and training \\
process. Nevertheless, this discourse may present \\
symbolic effectiveness in the player's \\
commercialization process. \\
Keywords: Soccer. Brazil. Identity. Talent. \\
\hline
\end{tabular}

Representaciones Identitarias en el Proceso de Selección de Talentos

Resumen: El objetivo del estudio es describir y analizar el proceso de detección y selección de talentos considerando las representaciones identitarias y prácticas en el cotidiano del fútbol. Utiliza como instrumento entrevistas semiestructuradas, aplicadas a los entrenadores y coordinadores de las categorías Sub 15, Sub 17 y Sub 20, y observadores técnicos en siete clubs de la primera división del fútbol brasileño. Se puede concluir que el discurso identitario sobre el ideal proclamado del fútbol brasileño, el fútbol arte, no orienta las acciones de los profesionales involucrados en el proceso de selección y entrenamiento de talentos. Sin embargo, este discurso puede tener eficacia simbólica en el proceso de comercialización de jugadores.

Palabras-clave: Fútbol. Brasil. Identidad. Talento.

Movimento, Porto Alegre, v. 16, n. 04, p. 135-150, outubro/dezembro de 2010. 


\section{REFERÊNCIAS}

ANDERSON, Benedict. Imagined communities: reflections on the origins and spread of nationalism. New York: Verso, 1983.

AGOSTINO, Gilberto. Vencer ou morrer: futebol, geopolítica e identidade nacional. Rio de Janeiro: FAPERJ/Mauad, 2002.

ALABARCES, Pablo. Fútbol y pátria: el fútbol y las narrativas de la nación en la Argentina. Buenos Aires: Prometeo Libros, 2002.

ARCHETTI, Eduardo. Argentina and the World Cup: in search of national identity. In: SUGDEN, J.; TOMLINSON, A. Hosts and champions: soccer cultures, national identities and the USA World Cup. Aldershot: Arena, 1994. p. 37-63.

ARCHETTI, Eduardo. Masculinities: football, polo and the tango in Argentina. New York: Berg, 1999.

CHRISTENSEN, Mette Krogh . An eye for talent: talent identification and the "practical sense" of Top-Level Soccer Coaches. Sociology of Sport Journal, v. 26, n. 3, p. 365-382, 2009.

COELHO, Paulo Vinícius. Bola fora: a história do êxodo do futebol brasileiro. São Paulo: Panda Books, 2009.

CUCHE, Denys. A noção de cultura nas ciências sociais. São Paulo: EDUSC, 1999.

DAMATTA. Roberto. Esporte na sociedade: um ensaio sobre o futebol brasileiro. In: DAMATTA, Roberto (Org.). Universo do futebol: esporte e sociedade brasileira. Rio de Janeiro: Pinakotheke, 1982. p. 19-42.

DAMO, Arlei Sander. Futebol e identidade social: uma leitura antropológica das rivalidades entre torcedores e clubes. Porto Alegre: Ed. UFRGS, 2002.

Do dom à profissão: uma etnografia do futebol espetáculo a partir da formação de jogadores no Brasil e na França.2005. 435 f. Tese (Doutorado em Antropologia Social) - Universidade Federal do Rio Grande do Sul, Porto Alegre, 2005.

FIENGO, Sergio Villena. Imaginando la nación a través del fútbol: el discurso de la prensa costarricense sobre la hazaña mundialista de Italia` 90. In: ALABARCES, Pablo (Org.). Peligro de gol: estudios sobre deporte y sociedad em America Latina Buenos Aires: Clacso, 2000. p. 131-153.

FIENGO, Sergio Villena. El fútbol y las identidades: prólogo a los estudios latinoamericanos. In: ALABARCES, Pablo (Org.). Futbologías: fútbol, identidad y violencia em América Latina. Buenos Aires: CLACSO, 2003. p. 21-35.

Movimento, Porto Alegre, v. 16, n. 04, p. 135-150, outubro/dezembro de 2010. 
Representações identitárias no processo ...

FRAGA, Alex Branco. Corpo, identidade e bom-mocismo: cotidiano de uma adolescência bem comportada. Belo Horizonte: Autêntica, 2000.

FREYRE, Gilberto. Prefácio. In: RODRIGUES FILHO, Mario. O negro no futebol brasileiro. Rio de Janeiro: Irmãos Pongetti, 1947.

GASTALDO, Édison Luis. "Os Campeões do Século": notas sobre a definição da realidade no futebol-espetáculo. Revista Brasileira de Ciências do Esporte, Campinas, v. 22, n. 1, p. 105-124. set.2000.

GIL, Gilson. O drama do "futebol-arte": o debate sobre a seleção nos anos 70 . Revista Brasileira de Ciências Sociais, São Paulo, n. 25, ano 9, p. 100-109, jun.1994.

GIULIANOTTI, Richard. Sociologia do futebol: dimensões históricas e socioculturais do esporte e das multidões. São Paulo: Nova Alexandria, 2002.

GUEDES, Simoni Lahud. O Brasil no campo de futebol: estudos antropológicos sobre os significados do futebol brasileiro. Rio de Janeiro: EDUFF, 1998.

HELAL, Ronaldo et al. Mídia, raça e idolatria: a invenção do país do futebol. Rio de Janeiro: Murad, 2001.

LA RADIOGRAFÍA DE KAKÁ. Marca.com, Madrid, 07.set.2009. Disponível em: <http://www.marca.com/2009/09/07/multimedia/graficos/1252315851.html>. Acesso em: 15 out.2009.

LEITE LOPES, José Sergio. A vitória do futebol que incorporou a pelada. Revista da USP - Dossiê Futebol, São Paulo, n. 22, p. 64-83, 1994.

MURAD, Maurício. Dos pés à cabeça: elementos básicos de sociologia do futebol. Rio de Janeiro: Irradiação Cultural, 1996.

PAOLI, Prospero Brum. Os estilos de futebol e os processos de seleção e detecção de talentos. 2007. 178f. Tese (Doutorado) - Programa de PósGraduação em Educação Física, Universidade Gama Filho, Rio de Janeiro, 2007.

RIAL, Carmen. Futebolistas brasileiros na Espanha: emigrantes porém.... Revista de Dialectología y Tradiciones Populares, v. LXI, p. 163-190, 2006.

RODRIGUES, Francisco Xavier Freire. Modernidade, disciplina e futebol: uma análise sociológica da produção social do jogador de futebol no Brasil. Sociologias, Porto Alegre. n. 11, p. 260-299, 2004.

ROSENFELD, Anatol. Negro, macumba e futebol. São Paulo: Perspectiva, 1993.

SANTOS NETO, José Moraes dos. Visão do jogo: primórdios do futebol no Brasil. São Paulo: Cosac \& Naif. Rio de Janeiro: Irradiação Cultural, 2002.

Movimento, Porto Alegre, v. 16, n. 04, p. 135-150, outubro/dezembro de 2010. 
SOARES, Antonio Jorge G. Futebol brasileiro e sociedade: a interpretação culturalista de Gilberto Freyre. In: ALABARCES, P. (Ed.). Futbologías: fútbol, identidad y violencia en América Latina. Clacso-Grupo de Trabajo Deporte e Cultura. Buenos Aires: Consejo Latinoamericano de Ciencias Sociales, 2003. P. 145-162.

SOARES, Antonio Jorge G.; BARTHOLO, Tiago Lisboa. Mercado, escola e a formação de jogadores de futebol no Brasil. In. REUNIÃO ANUAL DA ANPED, 32, 2009, Caxambu. Anais... Caxambu: ANPED, 2009.

SOARES, Antonio Jorge G.; LOVISOLO, Hugo. Futebol: a construção do estilo nacional. Revista Brasileira de Ciências do Esporte, Campinas, v. 25, n. 1, p. 129 - 143, set. 2003a.

SOARES, Antonio Jorge G. ; LOVISOLO, Hugo. Rápida difusão do futebol: variabilidade de estilo e padronização. Revista Eletrônica Polêmica, RJ- LABORE UERJ, v. 9, n. 2, p. 1-3, 2003b.

SOUZA, Camilo Araújo Maximo de et al. Difícil reconversão: futebol, projeto e destino em meninos brasileiros. Horizontes Antropológicos, Porto Alegre, $\mathrm{n}$. 30, p. 85-111, jul./dez. 2008.

TOLEDO, Luiz Henrique de. Futebol e teoria social: aspectos da produção científica brasileira (1982-2002). BIB - Revista Brasileira de Informação Bibliográfica em Ciências Sociais, v. 2, n. 52, p. 133-166, 2001.

VAZ, Alexandre Fernandez. Treinar o corpo, dominar a natureza: notas para uma análise do esporte com base no treinamento corporal. Caderno CEDES, Campinas, v. 19 , n. 48 , p. 89-108, ago.1999.

Movimento, Porto Alegre, v. 16, n. 04, p. 135-150, outubro/dezembro de 2010. 